\title{
An observational study of recess quality and physical activity in urban primary schools
}

\author{
Megan B Stellino \\ University of Northern Colorado \\ John Geldhof \\ Oregon State University
}

William Vincent Massey ( $\nabla$ william.massey@oregonstate.edu )

Oregon State University https://orcid.org/0000-0002-4002-3720

\section{Research article}

Keywords: School health, Adult engagement, Play, Obesity

Posted Date: February 24th, 2020

DOl: https://doi.org/10.21203/rs.2.24385/v1

License: (c) (i) This work is licensed under a Creative Commons Attribution 4.0 International License.

Read Full License

Version of Record: A version of this preprint was published at BMC Public Health on May 27th, 2020. See the published version at https://doi.org/10.1186/s12889-020-08849-5. 


\section{Abstract}

\section{Background}

To date, there is scant literature that examines the recess context concurrent with, but separate from, levels of physical activity. The primary purpose of the current study was to examine how recess quality impacted physical activity levels, and how this was moderated by gender. A secondary purpose was to examine if differences in children's engagement in activities occurred between recess sessions scored as low- or high- quality.

\section{Methods}

This was an observational study of children at 13 urban elementary schools in the U.S. Across the 13 schools, data were collected at 55 recess sessions, with 3,419 child-level observations ( $n=1,696$ boys; $n=$ 1,723 girls). Physical activity data were collected using Fitbit accelerometers, recess quality data were collected using the Great Recess Framework - Observational Tool (GRF-OT), recess engagement data were collected using the Observation of Playground Play (OPP), and basic psychological need satisfaction (BPNS) data were collected using a modified version of the BPNS for recess physical activity survey. Primary analyses were conducted using Hierarchical Linear Modeling (HLM) with children nested within recess sessions.

Results

Gender moderated the relationship between adult engagement and moderate-to-vigorous physical activity (MVPA) ( $b=.012 ; 95 \% \mathrm{Cl} .001, .024)$, student behavior and MVPA ( $b=-.014 ; 95 \% \mathrm{Cl}-.021,-.007)$, and student behaviors and light physical activity $(b=.009,95 \% \mathrm{Cl} .003, .015)$. Both boys and girls engaged in more play during recess sessions scored as high quality on the GRF-OT. Children reported higher levels of basic psychological need satisfaction at recesses sessions scored as high quality on the GRF-OT.

\section{Conclusions}

Results of the current study showed that the quality of the recess environment, and the interactions of both adults and students in that environment, need to be taken into consideration in future school-based recess studies.

\section{Background}

Low levels of physical activity (PA) remain a problem that contribute to the high obesity rates seen in children. Increasingly, schools have become a focus for physical activity interventions amongst researchers (1) particularly given the amount of time children spend in this environment. Unfortunately, children in the United States (U.S.) continue to lack meaningful opportunities for physical activity at school, despite research that shows time spent engaging in physical activity makes positive contributions to academics (2). Aside from PE, school-based recess is also a prime opportunity for physical activity 
within the school day. Specifically, recess has been shown to account for $42 \%$ of children's opportunities to be physically active in school (3), and up to $44 \%$ of step counts during the school day (4). Despite this, data from the 2012-2013 academic year in the United States (U.S.) suggest that $60 \%$ of school districts have no formal policy regarding daily recess. Of school-districts that have a recess policy, only $22 \%$ require daily recess for elementary school students, with less than half of these requiring at least 20 minutes of recess per day (5). While recent legislative efforts have been made to promote recess at the state level, only seven out of 50 U.S. states require daily recess for children during the school day (6).

Perhaps more concerning is the trends described above disproportionally affect children from disadvantaged backgrounds. Data show that children who go to large, urban schools; schools with a high minority population; and schools with low-income levels are the least likely to get access to recess, and often report the shortest amount of time dedicated to recess $(7,8)$. It is plausible that environmental factors affect children's access to physical activity opportunities in urban and low-income school systems. Notably, bullying and aggressive behavior have been reported on the playground at urban elementary schools $(9,10)$, which could result in fewer opportunities for students. Furthermore, access to space and equipment are thought to be central to recess facilitation (11), which could be lacking at lowincome, and/or urban schools. For example, a systematic review conducted by Erwin et al. (4) suggests that adding more playground equipment and providing a structured recess yields the largest effect on physical activity during recess. Yet, budgetary restraints could limit the purchase of equipment in lowincome school districts. Thus, there is a need to consider both access to recess, and the quality of the recess environment for promoting physical activity throughout the school day, particularly in low-income and urban environments.

Aside from addressing disparities to physical activity opportunities such as recess, a need also exists to examine barriers to, and facilitators for, physical activity when children do have access to discretionary time during the school day. One common area of focus has been on differences between activity levels for boys and girls, given that data has consistently shown that girls are less active during recess periods $(12-14)$. These data suggest that social determinants might play a role in children's behavior on the playground. In examining barriers to physical activity, Pawlowski and colleagues $(15,16)$ reported several gendered issues that may limit physical activity during recess. For example, elementary school girls reported wanting to play sports (i.e., ball games), but those were usually dominated by the boys on the playground (15). Moreover, activities at recess can be labeled along gender lines, with girls being expected to conform to more sedentary activities (16). While girls seem more interested in crossing gender borders at recess (17), boys in the Pawlowski et al. study (16) dominated the larger playground spaces (i.e., football pitch) often excluding girls during the game. Thus, it appears that there is a need for both variety of games and play spaces, as well as inclusive behavior on the playground, in an effort to more effectively promote physical activity at recess. Indeed, researchers have reported girls engage in similar levels of moderate-to-vigorous physical activity (MVPA) as boys when playing team sports (14) and that providing an activity of the week intervention can yield gains in physical activity (18). 
Another important consideration for examining behavior at recess is how perceptions of physical and emotional safety might impact physical activity behavior during recess. Previous research with child participants has suggested that conflict is a regular part of the playground experience $(19,20)$. Similarly, behavioral observations have suggested that bullying regularly takes place during recess periods (10). In terms of physical activity during recess, children have specifically discussed conflict as a barrier to play for boys and girls alike. Moreover, children have reported that a stronger presence by adults at recess might help to facilitate higher levels of play, as there would be a more neutral mediator to weigh in on games (16). This notion was supported by a recent study that showed adult engagement and supervision as a significant predictor of play for boys and girls during recess (21). Additional work has shown that the presence of recess interventions changes play patterns, specifically reducing non-engagement and increasing engagement in more traditional games such as four-square, hopscotch, and use of loose equipment (22)

In considering the potential barriers to physical activity at recess, multiple interacting factors are at play. Access to resources, school policies, the physical environment, various social determinants, and student behaviors all play various roles in facilitating, or impeding, physical activity at recess. Understanding optimal standards for facilitating physical activity during recess is currently needed, especially for those in urban and/or low-income schools who may have limited opportunities. To date, there is scant literature that examines the recess context concurrent with, but separate from, levels of physical activity. Recently, Massey and colleagues (23) developed an observational tool to measure environmental and social determinants of elementary school recess. Specifically, the Great Recess Framework - Observational Tool (GRF-OT) measures the safety and structure of the playground, adult engagement and supervision, as well as student behaviors. Given the overlap between the GRF-OT and researching examining potential barriers and facilitators to recess physical activity, there is a need to examine how the above-mentioned contextual factors, as measured by the GRF-OT, impact physical activity levels. As such, the primary purpose of the current study was to examine how recess quality impacted physical activity levels, and how this was moderated by gender. A secondary purpose was to examine if differences in children's engagement in activities occurred between recess sessions scored as low- or high- quality.

\section{Methods}

Institutional Review Board approval was obtained prior to the start of any study procedures (Concordia University Wisconsin ID: 932380-3; 926512-1). Additionally, all protocols and procedures were approved by the research board at the school district level, as well as the principal at each school. In an effort to ensure we could include a maximum number of children on the playground, a passive consent protocol was followed. Consent forms were sent home to each student and parents and students were given the opportunity to opt out of the current study. In accordance with school district policy on passive consent protocols, personally identifying information was not collected on participants.

\section{Participants}


Participants included children at 13 urban elementary schools in the U.S. Across the 13 schools, accelerometer data were collected at 55 recess sessions, with 3,419 child-level observations ( $n=1,696$ boys; $n=1,723$ girls). Observations of engagement in recess activities were collected at 61 recess sessions with 4,528 child-level observations ( $n=2243$ boys; $n=2285$ girls). The number of children within each recess session ranged from 12 to 117 with an average of 62.16 (SD = 26.34) children per recess. All schools enrolled in this study served children in low-income areas, with publicly available data showing that $78.8 \%$ of the student population is economically disadvantaged (12-out-of-13 schools $>50 \%$ of economically disadvantaged students; range $=22.5 \%-99.6 \%)$. Of the 13 schools, 10 were in the publicschool system, with three of these 10 schools being language immersion schools. Twelve of the 13 schools were exclusively elementary schools (i.e., grades 1-5), and one school also served middle school students (i.e., grades 4-8). Enrollment at each school ranged from 253 students to 690 students, with an average of 436 students per school.

\section{Measures}

Physical activity. The Fitbit Flex ${ }^{\mathrm{TM}}$ is a wrist worn triaxial accelerometer that uses proprietary algorithms to estimate steps counts and time spent in various activity levels. The Fitbit Flex provides the most simplistic user display of all Fitbit products, with only LED lights to represent progress towards daily goals (the default setting is 10,000 steps; 2000 steps per dot shown). This was thought to be advantageous, as participants would not be able to directly monitor their step counts of physical activity levels during recess. The Fitbit Flex can by synched wirelessly to a smart phone or tablet, and provides information on steps counts and time spend in various activity levels (i.e., sedentary, light, moderate, vigorous). For the purposes of the current study, the research team created anonymous accounts for each device that could only be accessed by the research team. Each account was assigned to either a male or female user, with national averages for height and weight being used for user demographic information. Fitbits were placed on students in their classroom, or in the lunch room, approximately 30 minutes prior to the start of recess. Data assessors recorded the exact start and stop times of recess so that data could be extracted to match the time stamp. Data were housed by a third-party vendor (Fitabase LLC, San Diego, California) and processed using 60 second epochs within the noted time stamp, the most sensitive setting available for this device. In child-based studies, both waist-worn (24) and wrist worn (25) Fitbit devices (Fitbit One and Fitbit Charge, respectively) have been shown to have consistent levels of step counts with Actigraph accelerometers, yet may over-estimate absolute number of steps, as well as time spent in MVPA. Additional research in young adult populations has shown moderate validity between the wrist-worn Fitbit Flex and the wrist-worn Actigraph GT3X + in free-living conditions (26), yet the Fitbit flex showed higher levels of variability, and was more likely to under-estimated activity levels.

Recess quality. The Great Recess Framework - Observational Tool (GRF-OT) was used as a measure of recess quality in the current study. The GRF-OT represents four domains of recess that include safety and structure of the playground, adult supervision and engagement, student behaviors, and transitions to and from the recess space (23). In the current study data was collected on three of the four sub-scales 
(transitions were excluded, as they account for the times immediately before and after recess and the focus of the current study was PA during recess). Items are scored on a 4-point scale by a live observer who was present at recess ( $4=$ highest quality; 1 = lowest quality). The safety and structure sub-scale examines the physical environment and access to equipment; the adult engagement and supervision subscale examines the number of adults present, their proximity to students, and whether or not they engage with students on the playground; and the student behaviors sub-scales examines student engagement, initiation of play, conflict, and conflict resolution. Each item and its associated scoring procedure can be found in Massey et al. 2018 (20). A complete scoring manual with detailed instructions is available at www.greatrecessframework.org. Data in the current study suggest acceptable levels of internal consistent for the safety and structure sub-scale $(a=.806)$, adult engagement and supervision sub-scale $(a=.736)$, and student behavior sub-scale $(a=.788)$. Previous research has shown support for the inter-rater reliability and factorial validity of the GRF-OT (23).

Engagement in recess activities. The different types of activities children engaged in during recess were measured using the Observations of Playground Play (OPP) (22). The OPP allows observes to code engagement in 32 common recess activities across eight different play domains. Observers are also able to write in observed behaviors within each of the eight domains to ensure all recess activities are captured. Previous research has been reported on the reliability of this assessment tool (22).

Basic psychological needs satisfaction (BPNS). A sub-sample of fourth and fifth grade students $(n=820)$ completed a modified version of the basic psychological need satisfaction scale (27). The original 21item questionnaire designed to assess individual perceptions of autonomy (7 items), competence (6 items), and relatedness (8 items) need satisfaction at work was modified to specifically examine children's need satisfaction during recess and reduced to two-items per scale to ensure comprehension for a younger population. Additionally, two items related to physical and emotional safety at recess were added to the scale. All responses corresponded to a 5-point Likert scale ( $5=$ high need satisfaction) on items such as "I feel like I can say my ideas about what I want to do at recess" (autonomy), "Kids tell me I am good at things I do at recess" (competence), "I really like the kids I play with at recess" (relatedness), and "I am safe when I am playing at recess" (safety).

\section{Procedures}

With the exception of one school that conducted concurrent indoor and outdoor recess periods, all recess data collection periods were conducted outside. Data collection took place between February and May in a large city in the Midwestern region of the United States. Recess periods ranged from 12 minutes to 40 minutes in length ( $M=21.12$ minutes; $S D=5.83$ minutes $)$ and primarily included traditional lunch recess periods. Schools maintained variable schedules, with some schools sending groups of students outside all at once, while others rotated the sessions with different children and different supervisors (e.g., only first through third graders at recess one, followed by only fourth and fifth graders at recess two). 
Outcome assessors arrived to the school approximately 60 minutes before the scheduled recess session to ensure students were properly fitted with activity monitoring devices. Each data collection period contained four study team members. Two members of the team were assigned to ensure compliance in terms of properly wearing the activity monitoring devices. The other two team members collected observational data throughout the entire recess session. Data using the GRF-OT were collected by the PI or a trained graduate student. In all cases, the recess environment was completely visible to the outcome assessor, and the outcome assessor moved throughout the playground in a discreet manner in an effort to observe patterns of interaction and behavior. Final scoring of each item was completed immediately after the recess session and took into account the aggregate patterns of behavior throughout the duration of the recess session. Data using the OPP were collected at five-minute intervals across each recess period. OPP data were then averaged to create a composite level of student engagement in different activities for each recess session.

\section{Data Analysis}

Prior to data analysis, Fitbit Flex data were screened and devices registering 0 step counts in the recess time recording were eliminated from the dataset. Time recordings of the beginning and ending of each recess session were kept to allow for specificity in data extraction when examining recess-based physical activity. Furthermore, Fitbit numbers were logged and tracked for each recess session to ensure which devices were in use for each session, and which devices were returned the end of each recess session. Given the varying times and number of students across recess sessions, we converted physical activity data to the percent of time spent in MVPA or light physical activity (LPA) during recess and used these percentages as the dependent variable in primary analyses.

Primary analyses were conducted using Hierarchical Linear Modeling (HLM) with children nested within recess sessions. Intercepts freely varied across recess sessions, while all primary predictors were entered as fixed effects. An unconditional nested model was first tested to examine possible recess-level effects for all dependent variables (i.e., physical activity levels). Next, models were fitted in which recess quality score indicators (i.e., adult engagement and supervision, student behaviors, safety and structure) were entered as predictors of physical activity levels while controlling for school as a fixed effect. Moderation was also tested by examining the interaction between gender (a level one predictor) and recess quality indicators (a level two predictor) on levels of physical activity during recess. Significant interactions were probed to examine the simple slopes and intercepts as a function of gender using the formula depicted below and as described by Preacher and colleagues (28), where ý $y_{00}$ represents the intercept, $y_{01}, y_{10}$ and $y_{11}$ are the regression coefficients, $x$ represents the focal predictor, and $w$ represents the moderator variable.

$\mathrm{y}_{\mathrm{ij}}=\mathrm{y}_{00}+\mathrm{y}_{10} \mathrm{x}_{1}+\mathrm{y}_{01} \mathrm{w}_{1}+\mathrm{y}_{11} \mathrm{w}_{1} \mathrm{x}_{1}$

Finally, trends across recess quality were examined relative to high- and low-quality recess sessions (i.e., one SD above and one SD below the sample mean). In general, high-quality recess sessions were 
characterized by safe physical environments (e.g., lack of hazardous materials), a broad range of equipment and activities to engage in play, prosocial student behaviors (e.g., initiating games, positive communication, lack of physical violence) and present and engaged adults. In contrast, low-quality recess sessions were often characterized as unsafe environments (e.g., glass and hazardous debris), limited or no equipment to use for game play, verbal and physical conflicts, and disengaged adults. Aggregate profiles of recess sessions in the upper and lower quartile for GRF-OT scores were created to examine differential patterns in the games and activities in which children participate in, and the psychological need satisfaction of children during recess.

\section{Results}

Descriptive statistics were calculated for all variables under study and can be found in Table 1. Results of the null models can be found in Table 2 (MVPA) and Table 3 (LPA). 
Table 1

Descriptive statistics.

\begin{tabular}{|c|c|c|c|}
\hline Variable & Mean & SD & Range (possible range) \\
\hline Total Recess Quality Score & 41.15 & 7.44 & $19-54(14-56)$ \\
\hline Safety and Structure of Environment & 14.96 & 3.49 & $6-20(5-20)$ \\
\hline Adult Engagement and Supervision & 10.61 & 2.49 & $5-16(4-16)$ \\
\hline Student Behaviors & 15.58 & 3.37 & $5-20(5-20)$ \\
\hline \multicolumn{4}{|l|}{ Physical Activity } \\
\hline Percent of time spent in MVPA & $50.54 \%$ & $35.96 \%$ & $0-100 \%$ \\
\hline Percent of time spent in LPA & $36.42 \%$ & $29.20 \%$ & $0-100 \%$ \\
\hline Psychological Need Satisfaction & 34.34 & 4.74 & $12-40(10-40)$ \\
\hline Autonomy & 7.94 & 1.91 & $2-10(2-10)$ \\
\hline Competence & 6.77 & 1.84 & $2-10(2-10)$ \\
\hline Relatedness & 8.23 & 1.68 & $2-10(2-10)$ \\
\hline Safety & 8.41 & 1.67 & $2-10(2-10)$ \\
\hline \multicolumn{4}{|c|}{$\begin{array}{l}\text { Engagement in Recess Activities (percent of } \\
\text { students) }\end{array}$} \\
\hline Equipment & $0 \%$ & $1 \%$ & $0-8 \%$ \\
\hline Organized activities & $30 \%$ & $24 \%$ & $0-92 \%$ \\
\hline Anti-social behavior & $1 \%$ & $3 \%$ & $0-22 \%$ \\
\hline Non-engaged in play & $30 \%$ & $22 \%$ & $0-84 \%$ \\
\hline Nature & $2 \%$ & $6 \%$ & $0-34 \%$ \\
\hline Running/chasing games & $17 \%$ & $15 \%$ & $0-76 \%$ \\
\hline Traditional playground games & $16 \%$ & $14 \%$ & $0-68 \%$ \\
\hline Rough and tumble play & $2 \%$ & $7 \%$ & $0-52 \%$ \\
\hline
\end{tabular}


Table 2

Unconditional nested model for percent of time spent in MVPA during recess

\begin{tabular}{|lccccccc|}
\hline \multicolumn{7}{|c|}{ Estimation of covariance parameters } \\
\hline Parameter & Estimate & s.e. & $\begin{array}{l}\text { Wald } \\
\mathrm{Z}\end{array}$ & $\begin{array}{l}\text { p- } \\
\text { value }\end{array}$ & $\begin{array}{l}95 \% \text { Cl of the } \\
\text { estimate }\end{array}$ & ICC \\
Residual & .122 & .003 & 40.99 & $<.001$ & $0.116,0.128$ & \\
\hline $\begin{array}{l}\text { Intercept Variance (Recess } \\
\text { Session) }\end{array}$ & .009 & .002 & 3.97 & $<.001$ & $.005, .014$ & 0.066 \\
\hline
\end{tabular}

Table 3

Unconditional nested model for percent of time spent in LPA during recess

\begin{tabular}{|lccccccc}
\hline \multicolumn{7}{|c|}{ Estimation of covariance parameters } \\
\hline Parameter & Estimate & s.e. & $\begin{array}{l}\text { Wald } \\
\text { Z }\end{array}$ & $\begin{array}{l}\text { p- } \\
\text { value }\end{array}$ & $\begin{array}{l}95 \% \text { Cl of the } \\
\text { estimate }\end{array}$ & ICC \\
\hline Residual & .082 & .002 & 41.00 & $<.001$ & $.078, .086$ & \\
\hline $\begin{array}{l}\text { Intercept Variance (Recess } \\
\text { Session) }\end{array}$ & .003 & .001 & 3.59 & $<.001$ & $.002, .006$ & 0.041 \\
\hline
\end{tabular}

An examination of predictors of the percent of time spent in MVPA at recess showed gender as the only significant predictor in the current study $(p=.001)$. However, moderation analyses revealed that gender moderated the relationship between adult engagement and MVPA $(p=.046)$, and student behavior and MVPA $(p=<.001)$. Results can be found in Table 4. Simple slopes analyses indicated that gender was not a significant predictor of percent of time spent in MVPA at low (M-1SD; $b=-.116 ; p=.107$ ), moderate (M; $b=-.085 ; p=.287)$ or high $(M+1 S D ; b=-.055, p=.542)$ levels of adult engagement and supervision. However, as can be seen in Fig. 1, the difference between boys' and girls' percent of time in MVPA was minimized as higher levels of adult engagement and supervision were observed. In examining student behaviors, simple slopes analyses revealed that gender was a significant predictor of percent time in MVPA at low (M-1SD; $b=-.381 ; p=<.001)$, moderate $(M ; b=-.429 ; p=<.001)$ and high $(M+1 S D ; b=$ $-.477, \mathrm{p}=<.001$ ) levels of prosocial student behavior. As can be seen in Fig. 2, boys' percent of time in MVPA was higher at recess sessions in which more prosocial student behaviors were observed; whereas girls' percent of time in MVPA was lower at recess sessions in which more prosocial student behaviors were observed. 
Table 4

Estimates of effects on percent of MVPA during recess

\begin{tabular}{|c|c|c|c|c|c|}
\hline \multicolumn{6}{|l|}{ Estimation of covariance parameters } \\
\hline Parameter & Estimate & s.e. & Wald Z & $\begin{array}{l}\mathrm{p}- \\
\text { value }\end{array}$ & $\begin{array}{l}95 \% \mathrm{Cl} \text { of the } \\
\text { estimate }\end{array}$ \\
\hline Residual & .110 & .003 & 40.99 & $<.001$ & $.105, .115$ \\
\hline Intercept Variance (recess) & .009 & .002 & 4.12 & $<.001$ & $.006, .014$ \\
\hline \multicolumn{6}{|l|}{ Estimation of fixed effects } \\
\hline Parameter & Estimate & s.e. & $\begin{array}{l}\text { T test } \\
\text { statistic }\end{array}$ & $\begin{array}{l}\mathrm{p}- \\
\text { value }\end{array}$ & $\begin{array}{l}95 \% \mathrm{Cl} \text { of the } \\
\text { estimate }\end{array}$ \\
\hline Intercept & .641 & .093 & 6.87 & $<.001$ & $.454, .827$ \\
\hline Gender & -.215 & .065 & -3.32 & .001 & $-.341,-.088$ \\
\hline School & -.002 & .005 & -.365 & .717 & $-.012, .008$ \\
\hline Safety and Structure of Environment & -.002 & .006 & -.380 & .705 & $-.014, .010$ \\
\hline Adult Engagement and Supervision & -.003 & .008 & -.354 & .724 & $-.018, .013$ \\
\hline Student behaviors & .003 & .006 & .519 & .605 & $-.009, .015$ \\
\hline $\begin{array}{l}\text { Gender * Safety and Structure of } \\
\text { Environment }\end{array}$ & .006 & .004 & 1.32 & .186 & $-.003, .014$ \\
\hline $\begin{array}{l}\text { Gender * Adult Engagement and } \\
\text { Supervision }\end{array}$ & .012 & .006 & 1.99 & .046 & $.001, .024$ \\
\hline Gender * Student behaviors & -.014 & .004 & -3.725 & $<.001$ & $-.021,-.007$ \\
\hline
\end{tabular}

In examining LPA, gender was once again the only significant predictor of LPA ( $p=.004)$. Gender also moderated the relationship between student behaviors and LPA $(p=.005)$. Results can be found in Table 5. Simple slopes analyses revealed that gender was a significant predictor of percent time in LPA at low (M-1SD; $b=.256 ; p=<.001)$, moderate $(M ; b=.286 ; p=<.001)$ and high $(M+1 S D ; b=.317, p=<.001)$ levels of prosocial student behavior. Specifically, girls recorded higher levels of LPA during recess sessions with high levels of prosocial student behavior; whereas boys recorded lower levels of LPA during recess sessions with high levels of prosocial student behavior (see Fig. 3). 
Table 5

Estimates of effects on percent of LPA during recess

\begin{tabular}{|c|c|c|c|c|c|}
\hline \multicolumn{6}{|l|}{ Estimation of covariance parameters } \\
\hline Parameter & Estimate & s.e. & Wald Z & $\begin{array}{l}\mathrm{p}- \\
\text { value }\end{array}$ & $\begin{array}{l}95 \% \mathrm{Cl} \text { of the } \\
\text { estimate }\end{array}$ \\
\hline Residual & .074 & .002 & 41.00 & $<.001$ & $.071, .078$ \\
\hline Intercept Variance (recess) & .003 & .001 & 3.60 & $<.001$ & $.002, .006$ \\
\hline \multicolumn{6}{|l|}{ Estimation of fixed effects } \\
\hline Parameter & Estimate & s.e. & $\begin{array}{l}\text { T test } \\
\text { statistic }\end{array}$ & $\begin{array}{l}\mathrm{p}- \\
\text { value }\end{array}$ & $\begin{array}{l}95 \% \mathrm{Cl} \text { of the } \\
\text { estimate }\end{array}$ \\
\hline Intercept & .201 & .063 & 3.21 & .002 & $.076, .326$ \\
\hline Gender & .152 & .053 & 2.86 & .004 & $.048, .257$ \\
\hline School & .004 & .003 & 1.18 & .241 & $-.003, .010$ \\
\hline Safety and Structure of Environment & .004 & .005 & .885 & .379 & $-.004, .012$ \\
\hline Adult Engagement and Supervision & .008 & .005 & 1.52 & .133 & $-.003, .019$ \\
\hline Student behaviors & -.006 & .004 & -1.41 & .163 & $-.014, .002$ \\
\hline $\begin{array}{l}\text { Gender* Safety and Structure of } \\
\text { Environment }\end{array}$ & -.002 & 004 & -.679 & .497 & $-.009, .005$ \\
\hline $\begin{array}{l}\text { Gender * Adult Engagement and } \\
\text { Supervision }\end{array}$ & -.008 & .005 & -1.50 & .133 & $-.017, .002$ \\
\hline Gender * Student behaviors & .009 & .003 & 2.83 & .005 & $.003, .015$ \\
\hline
\end{tabular}

\section{Engagement In Recess Activities}

Following analyses of physical activity at recess, patterns of play were compared for recess sessions at least one standard deviation above the mean recess quality score and at least one standard deviation below the mean recess quality score ( $n=952$ boys; $n=952$ girls). As can be seen in Fig. 4 , the largest differences were seen in non-engagement in play (e.g., talking with friends, watching others), with 61 percent of girls at low-quality recess sessions non-engaged in play as compared to 22 percent of girls at high quality recess sessions. Girls at high quality recess sessions also participated in more organized games than girls at low-quality recess sessions (e.g., dance, kickball, soccer; $23 \%$ vs. $9 \%$ ), and more traditional playground activities (e.g., four-square, jump ropes; $21 \%$ vs. $9 \%$ ). As seen in Fig. 5, a similar pattern was observed for boys as it related to non-engagement $(10 \%$ at high quality recess sessions vs. $36 \%$ at low quality recesses), participation in organized activities ( $52 \%$ at high quality recess sessions vs. 
$37 \%$ at low quality recesses), and participation in traditional playground activities ( $15 \%$ at high quality recess sessions vs. $5 \%$ at low quality recesses).

Finally, basic psychological need satisfaction scores were compared for those attending high-quality recess sessions (i.e., at least one SD above the mean) and those attending low-quality recess sessions (i.e., at least one SD below the mean). Results indicate that children at a high-quality recess session report higher levels of basic psychological need satisfaction at recess than children at a low-quality recess session $(t(324)=2.65 ; p=.004)$. An examination of the individual sub-scales revealed no group differences in competence or relatedness, however those at a high-quality recess reported higher levels of perceived autonomy at recess $t(333)=1.79 ; p=.037$ ) and higher levels of perceived safety at recess $(\mathrm{t}(306)=4.52 ; \mathrm{p}<.001)$.

\section{Discussion}

The primary purpose of the current study was to examine how contextual features of the playground impacted physical activity levels, and how this was moderated by gender. A secondary purpose was to examine patterns of engagement at recess to better understand how the quality of the environment shapes physically active behavior during this discretionary time period. Results of the current study showed that the quality of the recess environment, and the interactions of both adults and students in that environment, need to be taken into consideration in future school-based recess studies. In examining patterns of MVPA, results showed that higher levels of adult engagement and supervision reduced the disparity between boys' and girls' physical activity levels at recess. This finding is supported by previous research that shows higher levels of adult engagement predict higher levels of student engagement at recess (21), that children report teacher engagement as a positive influence on recess (29), and that teacher support is a facilitator of activity at recess (30). Moreover, given previous reports of social barriers girls face in being physically active at recess (e.g., boys dominating equipment and space; 15,16), it is likely that engaged adults on the playground help to facilitate equity in access to playground resources during recess.

An examination of physical activity levels at various levels of prosocial student behaviors showed that boys participated in higher levels of MVPA during recess sessions with high pro-social behaviors. For boys, at a high-quality recess session, higher levels of organized games (i.e., soccer, basketball, football) likely accounted for higher levels of MVPA. Notably, when prosocial behaviors were high (i.e., limited fighting, limited arguments, high levels of game initiation, high levels of conflict resolution) games went on uninterrupted, allowing boys to further engage in MVPA during recess. In contrast, girls participated in higher levels of MVPA during recess sessions with low pro-social behaviors. While contrary to expectations, the findings related to girls increased rates of MVPA at recess sessions with low pro-social behaviors can partially be explained by activity patterns at recess. Popular activities for girls at high quality recess sessions included traditional playground games (e.g., 4-square, hopscotch) as well as organized activities (e.g., dance), which are generally aligned with LPA, as opposed to MVPA. As shown in Fig. 3, LPA was higher for girls at recess sessions with high levels of pro-social behavior. Thus, when 
prosocial behaviors were high, games and activities in which girls were participating in had fewer interruptions. However, at low-quality recess sessions, or recess sessions characterized as having low levels of prosocial behavior (i.e., higher rates of fighting and arguing, low levels of conflict resolution), it is possible that otherwise unengaged girls engaged in intermittent bouts of MVPA. These data are consistent with previous data of boys and girls play patterns at recess $(15,16,21,22)$, yet also underscore the importance of examining the context in which physical activity occurs. Notably, while increase levels of PA remains a goal of many researchers, data from the current study underscores the need to understand the quality of the PA environment as it relates to children's holistic development.

Previous research has also examined psychological need satisfaction and motivation for physical activity at recess. Notably, Stellino and Sinclair (27) reported that psychological need satisfaction was predictive of physical activity motivation at recess, and that autonomy was predictive of physical activity during recess. Results of the current study support these data, and further suggest that a high-quality recess environment can help facilitate basic psychological need satisfaction. Notably, children at high-quality recess sessions reported higher overall psychological need satisfaction, higher autonomy for recess physical activity, and higher levels of perceived safety than those at low-quality recess sessions. These findings suggest that structuring the recess environment to include a variety of play opportunities and training adults to be actively engaged in recess are autonomy supportive, as opposed to controlling strategies. While recess remains one of few discretionary time periods during the school day, data suggests that implementing evidence-based practices during recess can help to enhance this discretionary time and satisfy student's basic psychological needs of autonomy, competence, and relatedness.

\section{Strengths And Limitations}

Taken together, the major strengths of this study include a multifaceted examination of recess within an under-researched population - urban elementary school students in low income schools. Further, the results of this study shed important light on future recess research. Notably, the equivocal findings of various interventions on physical activity promotion and social behaviors (31-33) warrant a more nuanced understanding of recess, particularly in under-resourced communities. The current study suggests the need for multi-faceted interventions that concurrently focus on increased access to recess, increased access to equipment and play spaces, positive and encouraging adult behavior, and pro-social student behavior. Indeed, perhaps the short-comings in previous intervention studies rely to singular or dual-purpose interventions, rather than a focus on multiple interventions taking place simultaneously.

The major limitations in the current study are the reduced sample size due to analysis taking place at the group level, the cross-sectional nature of the data collection, and limitations with the use of Fitbits to capture objective physical activity in child populations. Because children engage in more intermittent bouts of PA, particularly during recess, shorter measurement intervals are thought to provide more accurate estimates of time spent in various PA intensities. In a study examining differences in MVPA for children during physical education classes, McClain and colleagues (34) compared direct observation 
and accelerometry at various epoch lengths. Results showed that estimates of MVPA were lower when using accelerometry, as compared to direct observation regardless of epoch length. However, longer epoch lengths were associated with lower MVPA counts. Similarly, more recent research has shown lower estimates of MVPA in children when using a 60 second epoch as opposed to a 15- or 5- second measurement period (35). Moreover, Banda and colleagues (35) reported that increased epoch length may over-estimate LPA in children as increased epoch time was associate with sedentary behavior being reclassified as LPA. Given this, it is possible that MVPA was under-estimated based on the duration and intensity of various activities engaged in during recess; whereas LPA may have been over-estimated. However, concurrent observational data of engagement in recess activities supports the overall pattern of results; specifically, higher levels of engagement in activities associated with increased PA during high- as opposed to low-quality recess sessions.

\section{Conclusions}

Recess remains a critical opportunity for children to be physical active during the school day. Results of the current study suggest that increasing adult engagement and facilitating higher levels of pro-social behavior are important to not only physical activity promotion at recess, but also children's psychological need satisfaction.

\section{Abbreviations}

PA

Physical Activity

US

United States

PE

Physical Education

MVPA

Moderate-to-Vigorous Physical Activity

GRF-OT

Great Recess Framework - Observational Tool

LPA

Light Physical Activity

OPP

Observations of Playground Play

BPNS

Basic Psychological Need Satisfaction

HLM

Hierarchical Linear Modeling

SD

Standard Deviation 


\section{Declarations}

Ethics Approval. Ethics approval was provided by the institutional review board at Concordia University Wisconsin (ID: 932380-3; 926512-1). The need for consent was waived as no individual level data were collected. The PI (WVM) was previously faculty at Concordia University Wisconsin.

Consent for Publication. Not applicable.

Availability of Data and Materials. The datasets used and/or analysed during the current study are available from the corresponding author on reasonable request.

Competing Interests. The authors declare that they have no competing interests

Funding. Funding for this study was provided by Playworks Education Energized. The funding agency was not involved in data collection, analysis, or interpretation.

Author Contributions. WVM designed the study, trained all data assessors, assisted with data collection analyzed the data, interpreted the data, and drafted the manuscript. MBS assisted with study design, interpretation, and writing of the manuscript. JG assisted in data analysis, data interpretation, and editing of the manuscript. All authors have given their final approval for the work to be published and have agreed to take accountability for all aspects of the work.

Acknowledgments. Not Applicable.

\section{References}

1. Dobbins M, Husson H, DeCorby K, LaRocca RL. School-based physical activity programs for promoting physical activity and fitness in children and adolescents aged 6 to 18 . Cochrane Database Syst Rev. 2013 Feb 28;(2):CD007651.

2. Rasberry CN, Lee SM, Robin L, Laris BA, Russell LA, Coyle KK, et al. The association between schoolbased physical activity, including physical education, and academic performance: a systematic review of the literature. Prev Med. 2011 Jun;52 Suppl 1:S10-20.

3. Robert Wood Johnson Foundation. Recess rules: Why the undervalued playtime may be America's best investment for healthy kids and healthy schools report [Internet]. 2007. Available from: http://www.rwjf.org/content/dam/farm/reports/reports/2007/rwjf18060

4. Erwin H, Abel M, Beighle A, Noland MP, Worley B, Riggs R. The Contribution of Recess to Children's School-Day Physical Activity. J Phys Act Health. 2012 Mar 1;9(3):442-8.

5. US Centers for Disease Control. Strategies for supporting recess in elementary schools, update for the 2012-13 school year [Internet]. Available from: https://www.cdc.gov/healthyschools/npao/pdf/LWP_Recess_Brief_2012_13.pdf.

6. Shafer M, Whitehouse E. State policies on physical activity in schools [Internet]. Council of State Governments; 2018 [cited 2020 Jan 20]. Available from: 
http://knowledgecenter.csg.org/kc/system/files/CR_activity_school.pdf

7. Barros RM, Silver EJ, Stein RE. School recess and group classroom behavior. Pediatrics [Internet]. 2009 [cited 2019 Jun 25];123(2):431-6. Available from: http://pediatrics.aappublications.org/cgi/doi/10.1542/peds.2007-2825

8. Monnat SM, Lounsbery MAF, McKenzie TL, Chandler RF. Associations between demographic characteristics and physical activity practices in Nevada schools. Prev Med [Internet]. 2017 Feb [cited 2020 Jan 20];95:S4-9. Available from:

https://linkinghub.elsevier.com/retrieve/pii/S0091743516302365

9. Anderson-Butcher D, Newsome WS, Nay S. Social Skills Intervention during Elementary School Recess: A Visual Analysis. Child Sch. 2003;25(3):135-46.

10. Massey WV, Stellino MB, Holliday M, Godbersen T, Rodia R, Kucher G, et al. The impact of a multicomponent physical activity programme in low-income elementary schools. Health Educ $\mathrm{J}$. 2017;76(5):517-530.

11. Huberty JL, Beets MW, Beighle A, Welk G. Environmental modifications to increase physical activity during recess: preliminary findings from ready for recess. J Phys Act Health. 2011 Sep;8 Suppl 2:S249-256.

12. Viciana J, Mayorga-Vega D, Martínez-Baena A. Moderate-to-Vigorous Physical Activity Levels in Physical Education, School Recess, and After-School Time: Influence of Gender, Age, and Weight Status. J Phys Act Health. 2016;13(10):1117-23.

13. Saint-Maurice PF, Welk GJ, Silva P, Siahpush M, Huberty J. Assessing children's physical activity behaviors at recess: a multi-method approach. Pediatr Exerc Sci. 2011 Nov;23(4):585-99.

14. Baquet G, Ridgers ND, Blaes A, Aucouturier J, Van Praagh E, Berthoin S. Objectively assessed recess physical activity in girls and boys from high and low socioeconomic backgrounds. BMC Public Health. 2014 Feb 21;14:192.

15. Pawlowski CS, Tjørnhøj-Thomsen T, Schipperijn J, Troelsen J. Barriers for recess physical activity: a gender specific qualitative focus group exploration. BMC Public Health. 2014 Jun 23;14(1):639.

16. Pawlowski CS, Ergler C, Tjørnhøj-Thomsen T, Schipperijn J, Troelsen J. "Like a Soccer Camp for Boys": A Qualitative Exploration of Gendered Activity Patterns in Children's Self-Organized Play during School Recess. Eur Phys Educ Rev. 2015 Aug;21(3):275-91.

17. Boyle DE, Marshall NL, Robeson WW. Gender at Play: Fourth-Grade Girls and Boys on the Playground. Am Behav Sci. 2003 Jun 1;46(10):1326-45.

18. Stellino MB, Sinclair CD, Partridge JA, King KM. Differences in children's recess physical activity: recess activity of the week intervention. J Sch Health. 2010 Sep;80(9):436-44.

19. Ridgers ND, Stratton G, McKenzie TL. Reliability and validity of the System for Observing Children's Activity and Relationships during Play (SOCARP). J Phys Act Health. 2010 Jan;7(1):17-25.

20. Pawlowski CS, Schipperijn J, Tjørnhøj-Thomsen T, Troelsen J. Giving children a voice: Exploring qualitative perspectives on factors influencing recess physical activity. Eur Phys Educ Rev. 2018 Feb 1;24(1):39-55. 
21. Massey WV, Stellino MB, Fraser M. Individual and environmental correlates of school-based recess engagement. Prev Med Rep. 2018 Sep 1;11:247-53.

22. Massey WV, Ku B, Stellino MB. Observations of playground play during elementary school recess. BMC Res Notes [Internet]. 2018 Oct 23 [cited 2019 Aug 20];11. Available from: https://www.ncbi.nlm.nih.gov/pmc/articles/PMC6199697/

23. Massey WV, Stellino MB, Mullen SP, Claassen J, Wilkison M. Development of the great recess framework - observational tool to measure contextual and behavioral components of elementary school recess. BMC Public Health. 2018 Mar 22;18(1):394.

24. Hamari L, Kullberg T, Ruohonen J, Heinonen OJ, Díaz-Rodríguez N, Lilius J, et al. Physical activity among children: objective measurements using Fitbit One ${ }^{\circledR}$ and ActiGraph. BMC Res Notes [Internet]. 2017 Apr 20 [cited 2019 Aug 20];10. Available from: https://www.ncbi.nlm.nih.gov/pmc/articles/PMC5397828/

25. Voss C, Gardner RF, Dean PH, Harris KC. Validity of Commercial Activity Trackers in Children With Congenital Heart Disease. Can J Cardiol. 2017;33(6):799-805.

26. Sushames A, Edwards A, Thompson F, McDermott R, Gebel K. Validity and Reliability of Fitbit Flex for Step Count, Moderate to Vigorous Physical Activity and Activity Energy Expenditure. PloS One. 2016;11(9):e0161224.

27. Stellino MB, Sinclair CD. Psychological Predictors of Children's Recess Physical Activity Motivation and Behavior. Res Q Exerc Sport. 2013 Jun 1;84(2):167-76.

28. Preacher KJ, Curran PJ, Bauer DJ. Computational Tools for Probing Interactions in Multiple Linear Regression, Multilevel Modeling, and Latent Curve Analysis. J Educ Behav Stat. 2006 Dec 1;31(4):437-48.

29. Parrish A-M, Yeatman H, Iverson D, Russell K. Using interviews and peer pairs to better understand how school environments affect young children's playground physical activity levels: a qualitative study. Health Educ Res. 2012 Apr;27(2):269-80.

30. Stanley RM, Boshoff K, Dollman J. Voices in the playground: A qualitative exploration of the barriers and facilitators of lunchtime play. J Sci Med Sport. 2012 Jan 1;15(1):44-51.

31. Bundy A, Engelen L, Wyver S, Tranter P, Ragen J, Bauman A, et al. Sydney Playground Project: A Cluster-Randomized Trial to Increase Physical Activity, Play, and Social Skills. J Sch Health. 2017 Oct 1;87(10):751-9.

32. Mayfield CA, Child S, Weaver RG, Zarrett N, Beets MW, Moore JB. Effectiveness of a Playground Intervention for Antisocial, Prosocial, and Physical Activity Behaviors. J Sch Health. 2017 May $1 ; 87(5): 338-45$.

33. Farmer VL, Williams SM, Mann JI, Schofield G, McPhee JC, Taylor RW. The effect of increasing risk and challenge in the school playground on physical activity and weight in children: a cluster randomised controlled trial (PLAY). Int J Obes 2005. 2017;41(5):793-800.

34. Mcclain JJ, Abraham TL, Brusseau TA, Tudor-Locke C. Epoch Length and Accelerometer Outputs in Children: Comparison to Direct Observation. Med Sci Sports Exerc [Internet]. 2008 Dec [cited 2020 
Jan 21];40(12):2080-7. Available from: https://insights.ovid.com/crossref?an=00005768200812000-00010

35. Banda JA, Haydel KF, Davila T, Desai M, Bryson S, Haskell WL, et al. Effects of Varying Epoch Lengths, Wear Time Algorithms, and Activity Cut-Points on Estimates of Child Sedentary Behavior and Physical Activity from Accelerometer Data. Pappalardo F, editor. PLOS ONE [Internet]. 2016 Mar 3 [cited 2020 Jan 21];11(3):e0150534. Available from: https://dx.plos.org/10.1371/journal.pone.0150534

\section{Figures}

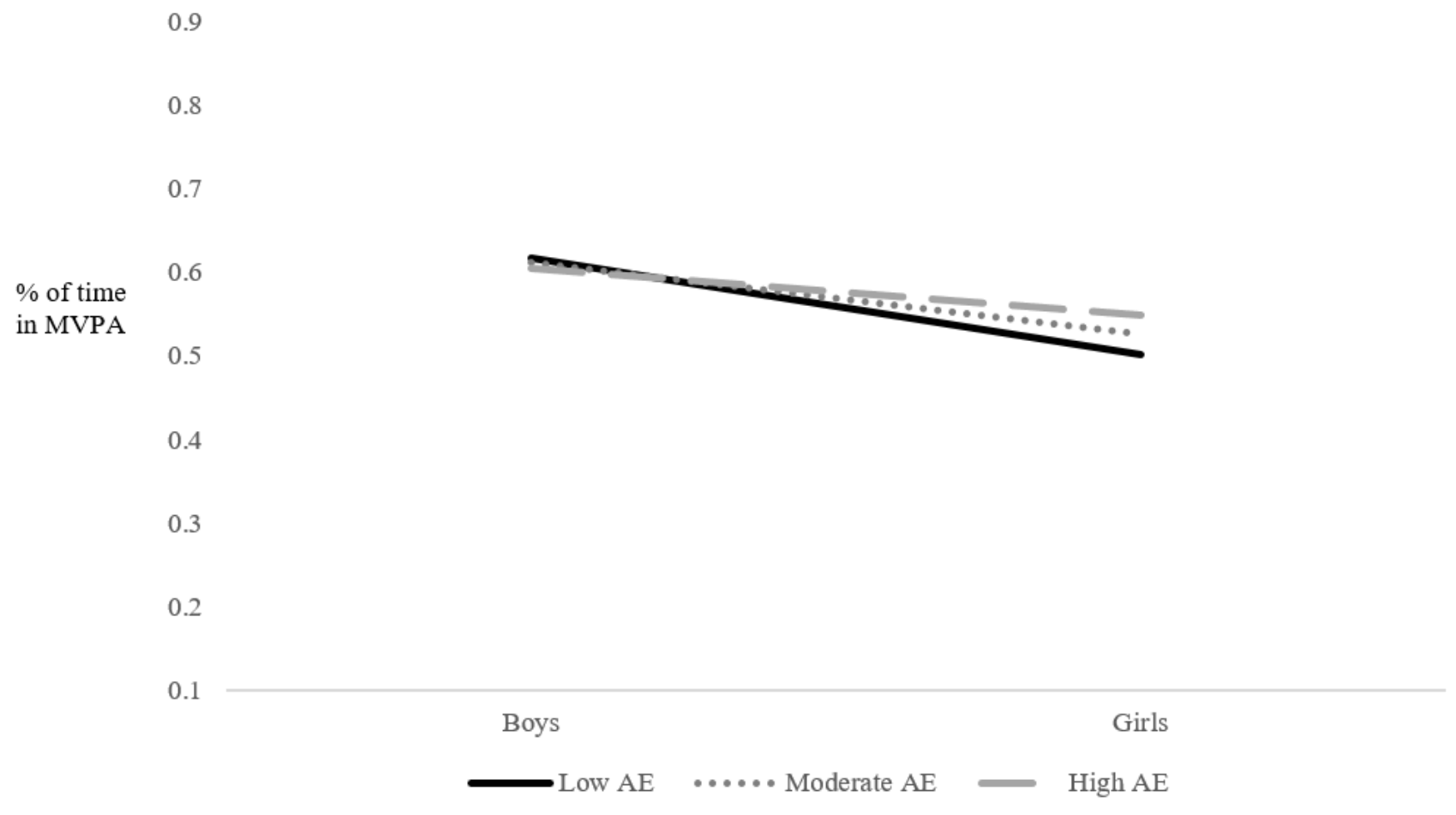

Figure 1

Gender x Adult engagement and supervision interaction for percentage of time in MVPA during recess. 


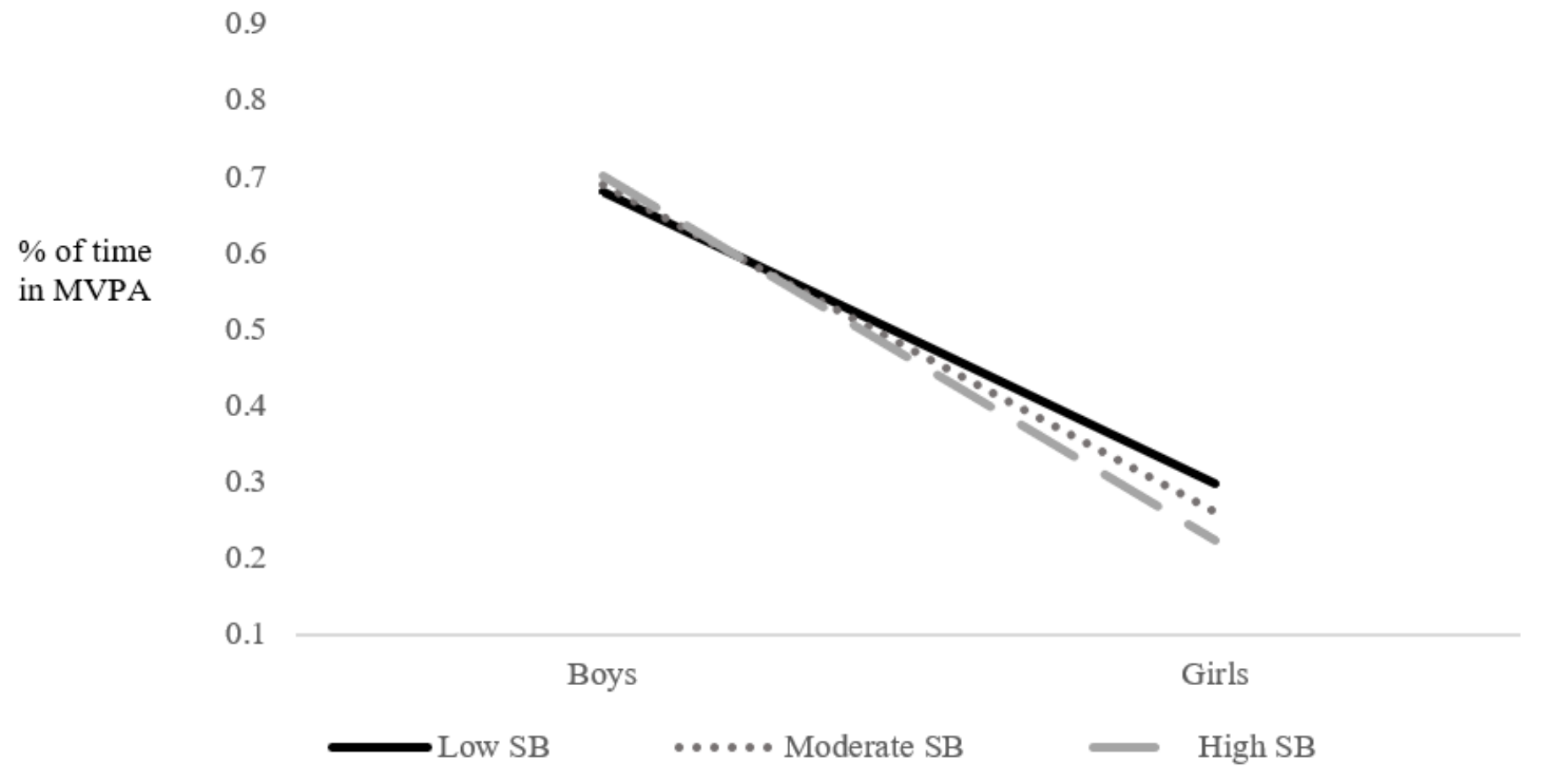

Figure 2

Gender $x$ Student behavior interaction for percentage of time in MVPA during recess.

0.5

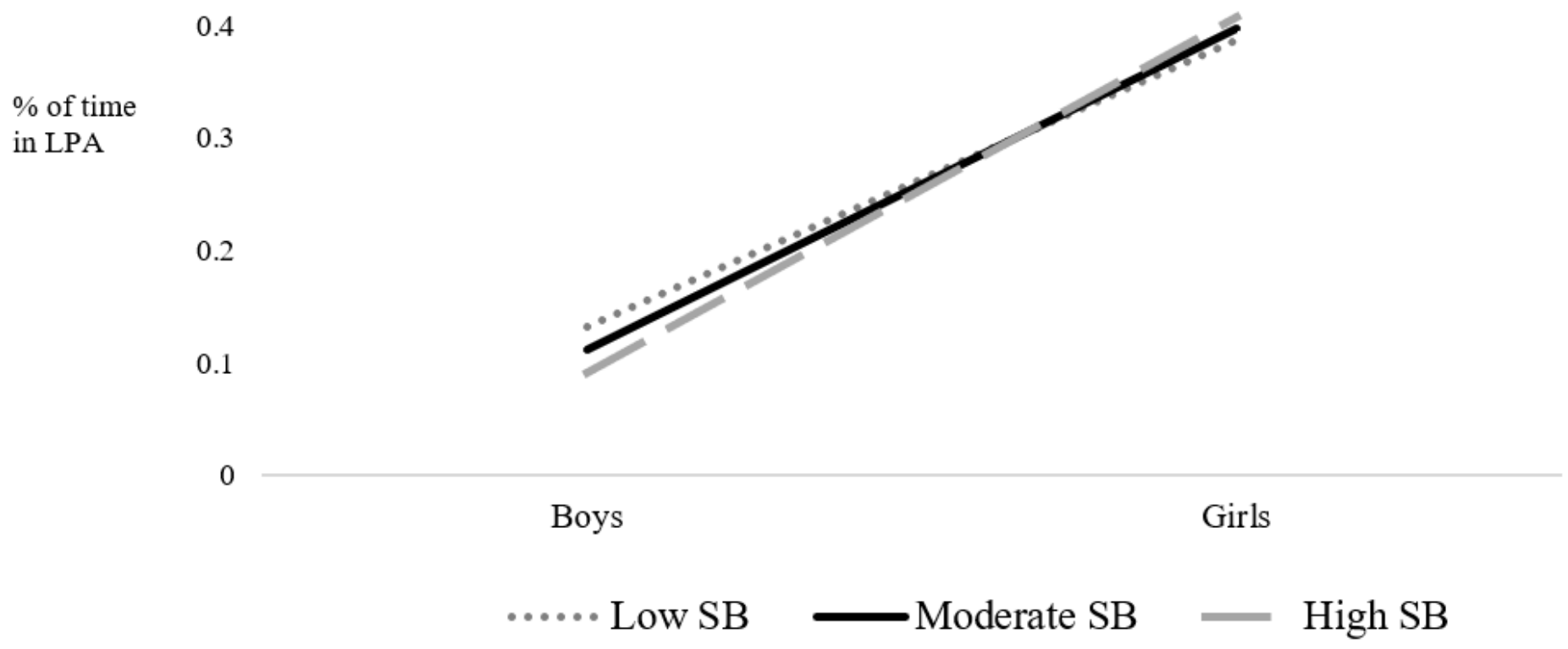

Figure 3 
Gender $x$ Student behavior interaction for percentage of time in light physical activity during recess.

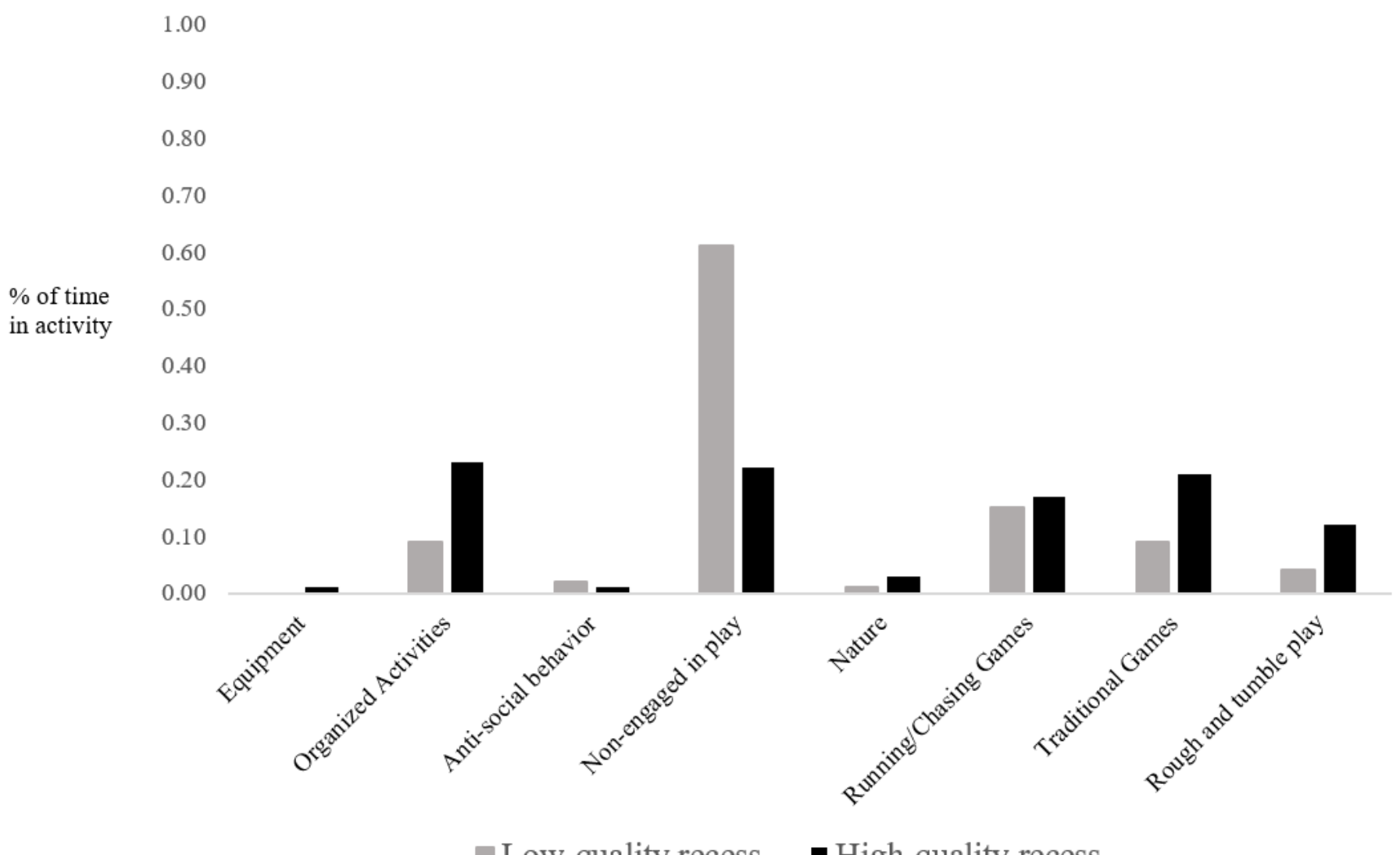

Figure 4

Differences in girls' engagement in play at high-versus low-quality recess sessions

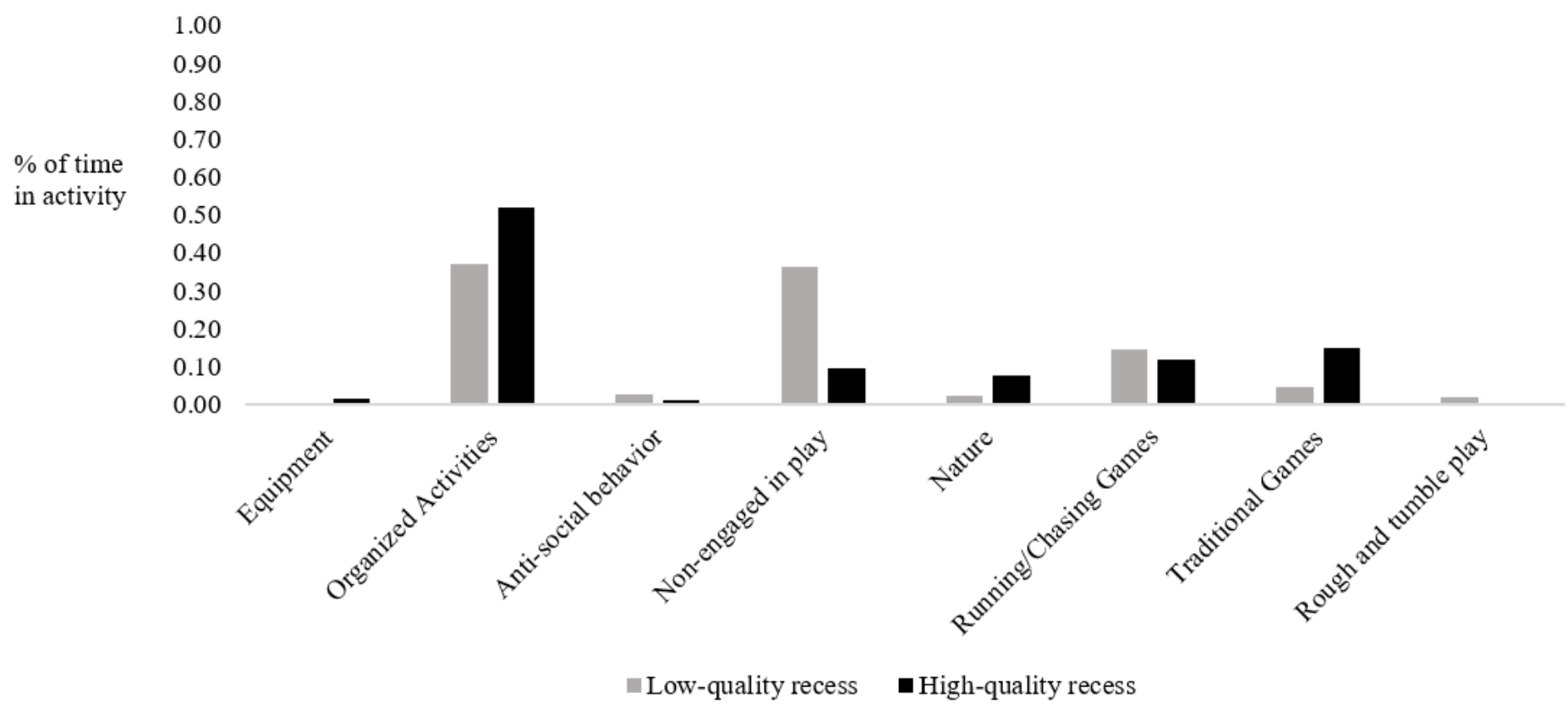


Figure 5

Differences in boys' engagement in play at high-versus low-quality recess sessions

\section{Supplementary Files}

This is a list of supplementary files associated with this preprint. Click to download.

- PsychNeedSatisfactionQuestionnaireShort.docx 